\title{
Central IKK $\beta$ inhibition prevents air pollution mediated peripheral inflammation and exaggeration of type II diabetes
}

\author{
Cuiqing Liu ${ }^{1,2+}$, Laura K Fonken ${ }^{2 \dagger}$, Aixia Wang ${ }^{2}$, Andrei Maiseyeu ${ }^{3}$, Yuntao Bai ${ }^{2}$, Tse-Yao Wang ${ }^{2}$, Santosh Maurya ${ }^{2}$, \\ Yi-An Ko ${ }^{4}$, Muthu Periasamy ${ }^{2}$, Timothy Dvonch ${ }^{5}$, Masako Morishita ${ }^{5}$, Robert D Brook ${ }^{5}$, Jack Harkema ${ }^{6}$, \\ Zhekang Ying ${ }^{3}$, Bhramar Mukherjee ${ }^{4}$, Qinghua Sun ${ }^{2}$, Randy J Nelson ${ }^{2}$ and Sanjay Rajagopalan ${ }^{3 *}$
}

\begin{abstract}
Background: Prior experimental and epidemiologic data support a link between exposure to fine ambient particulate matter $\left(<2.5 \mu \mathrm{m}\right.$ in aerodynamic diameter, $\mathrm{PM}_{2.5}$ ) and development of insulin resistance/Type II diabetes mellitus (Type II DM). We investigated the role of hypothalamic inflammation in $\mathrm{PM}_{2.5}$-mediated diabetes development.

Methods: KKay mice, a genetically susceptible model of Type II DM, were assigned to either concentrated $\mathrm{PM}_{2.5}$ or filtered air (FA) for 4-8 weeks via a versatile aerosol concentrator and exposure system, or administered intra-cerebroventricular with either IKK inhibitor (IMD-0354) or TNFa antibody (infliximab) for 4-5 weeks simultaneously with $\mathrm{PM}_{2.5}$ exposure. Glucose tolerance, insulin sensitivity, oxygen consumption and heat production were evaluated. At euthanasia, blood, spleen, visceral adipose tissue and hypothalamus were collected to measure inflammatory cells using flow cytometry. Standard immunohistochemical methods and quantitative PCR were used to assess targets of interest.

Results: $\mathrm{PM}_{2.5}$ exposure led to hyperglycemia and insulin resistance, which was accompanied by increased hypothalamic IL-6, TNFa, and IKK 3 mRNA expression and microglial/astrocyte reactivity. Targeting the NFKB pathway with intra-cerebroventricular administration of an IKK 3 inhibitor [IMD-0354, $n=8$ for each group)], but not TNFa blockade with infliximab [( $n=6$ for each group], improved glucose tolerance, insulin sensitivity, rectified energy homeostasis $\left(\mathrm{O}_{2}\right.$ consumption, $\mathrm{CO}_{2}$ production, respiratory exchange ratio and heat generation) and reduced peripheral inflammation in response to $\mathrm{PM}_{2.5}$.

Conclusions: Central inhibition of IKK 3 prevents $\mathrm{PM}_{2.5}$ mediated peripheral inflammation and exaggeration of type II diabetes. These results provide novel insights into how air pollution may mediate susceptibility to insulin resistance and Type II DM.
\end{abstract}

Keywords: Diabetes, Particulate matter, Hypothalamus, Inflammation, IKKß

\section{Background}

According to the recently published global burden of disease statement, among risk factors, indoor and outdoor air-pollution represents the third and tenth leading causes of global morbidity and mortality respectively [1]. The risks posed by inhaled pollutants are primarily mediated

\footnotetext{
* Correspondence: srajagopalan@medicine.umaryland.edu

${ }^{\dagger}$ Equal contributors

${ }^{3}$ Division of Cardiovascular Medicine, University of Maryland, Baltimore, MD, USA

Full list of author information is available at the end of the article
}

by particulate matter content, especially particles $<2.5 \mu \mathrm{m}$ in aerodynamic diameter $\left(\mathrm{PM}_{2.5}\right)$ [2,3]. Both epidemiologic studies and experimental evidence support adverse cardiometabolic consequences of air-pollution exposure, including worsening of whole body insulin sensitivity, promotion of hepatic endoplasmic reticulum stress, brown adipose dysfunction, and peripheral inflammation [4-6].

Insulin resistance (IR) is widely believed to evolve as a consequence of inflammatory signaling in the peripheral metabolic tissues such as the liver, adipose tissue, skeletal muscle, and/or the vasculature [7-9]. The central nervous

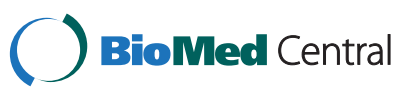


system (CNS), particularly the hypothalamus, is a key regulator of metabolic control. In diet-induced obesity, early onset hypothalamic inflammation has been implicated in central resistance to fuel-sensing hormones, loss of homeostatic control of food intake, and changes in energy expenditure. These changes in the hypothalamus have been noted in rodent models, as well as in humans [10-12]. In time course studies, peripheral inflammation takes weeks to develop following initiation of a high fat diet, whereas hypothalamic inflammation occurs rapidly within $24 \mathrm{hrs}$ and prior to substantial weight gain and peripheral inflammation [13,14]. Targeting inflammation in the hypothalamus by the inactivation of IкB kinase or TNF $\alpha$ blockade protects against defective thermogenesis, obesity and IR $[15,16]$, suggesting that hypothalamic dysfunction may precede and mechanistically contribute to obesity-associated IR and Type II diabetes (Type II DM). We hypothesized that inhalation of concentrated $\mathrm{PM}_{2.5}$ would result in hypothalamic inflammation and exert effects on peripheral inflammation and IR and tested this hypothesis in a genetically susceptible mouse model of Type II DM.

\section{Results}

\section{Exposure characteristics}

Three batches of KKay mice were exposed by inhalation to either filtered air (FA) or concentrated ambient $\mathrm{PM}_{2.5}$ during three distinct exposure periods which were named as Exposure 1, Exposure 2, and Exposure 3 for convenience of description (Figure 1A). During Exposure 1, mice were exposed for 6 h/d, 5 d/wk, 5 weeks or 8 weeks. For Exposure 2 , mice were treated (ICV) with infliximab or artificial CSF through an implanted ICV catheter (see ICV drug infusion protocol) and exposed for $6 \mathrm{~h} / \mathrm{d}, 5 \mathrm{~d} / \mathrm{wk}$, for 5 weeks. For Exposure 3, mice were treated with IMD-0354 (ICV) or vehicle (DMSO) and exposed for $6 \mathrm{~h} / \mathrm{d}, 5 \mathrm{~d} / \mathrm{wk}$, for 4 weeks.

During the three exposure periods, mean concentration of $\mathrm{PM}_{2.5}$ was $9.6,10.7$ and $6.3 \mu \mathrm{g} / \mathrm{m}^{3}$ in the ambient air, 2.3, 2.3 and $2.7 \mu \mathrm{g} / \mathrm{m}^{3}$ in the filtered air chamber, $116.9,139.5$ and $73.6 \mu \mathrm{g} / \mathrm{m}^{3}$ in the concentrated $\mathrm{PM}_{2.5}$ exposure chamber respectively. This represented 12.2, 13.1 and 11.8-fold concentration over ambient levels respectively (Figure $1 \mathrm{~B}$ ). For the purposes of convenience, concentrated ambient $\mathrm{PM}_{2.5}$ exposure is referred to $\mathrm{PM}_{2.5}$ in this manuscript unless specified otherwise.

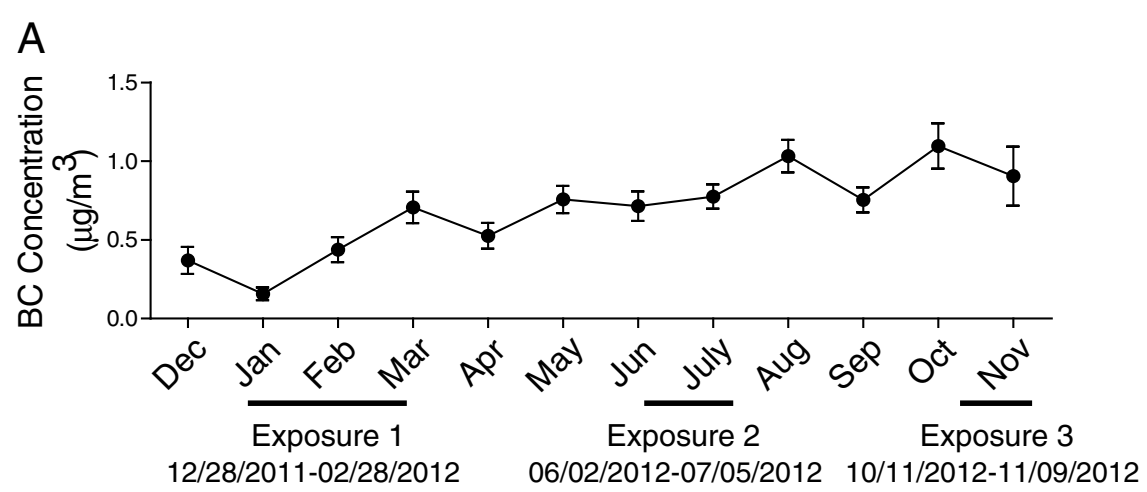

B

Exposure 1

Exposure 2

Exposure 3
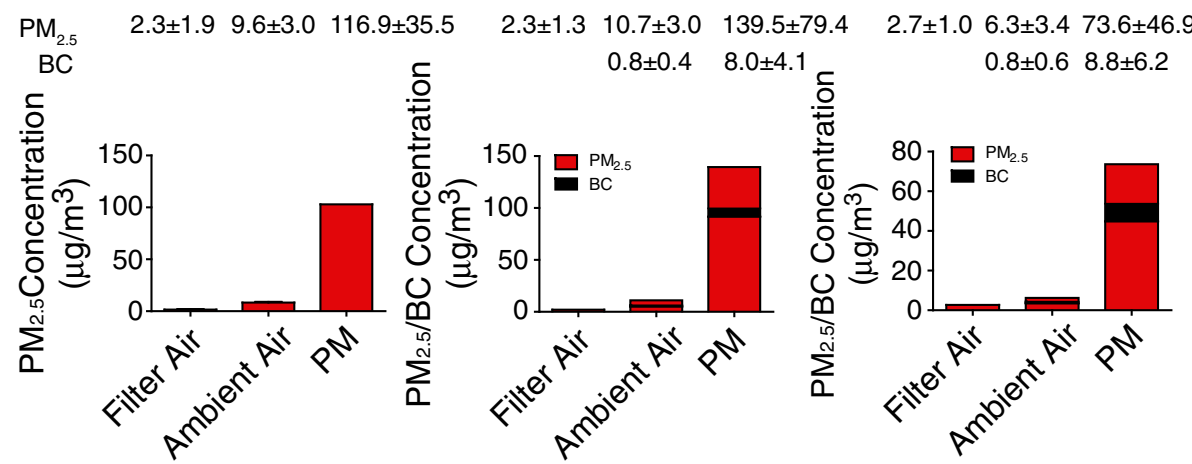

Figure $1 \mathrm{PM}_{2.5}$ and $\mathrm{BC}$ concentration at the study site. A, BC concentration in the ambient air from Dec. 2011-Nov. 2012. Exposure 1-Exposure 3 was labeled under the $\mathrm{X}$-axis with exact date information. $\mathbf{B}, \mathrm{PM}_{2.5}$ and $\mathrm{BC}$ concentration in the filter air, ambient air and concentrated ambient air for different exposure periods. The mean values of $\mathrm{PM}_{2.5} / \mathrm{BC}$ concentration were shown above the according bar graphs in different exposure period. $\mathrm{BC}$ denotes black carbon. 
Figure 1A provides the mean concentration of black carbon in the ambient air at the site of exposure facility, for the period Dec. 2011-Nov. 2012. The mean concentration of black carbon in the $\mathrm{PM}_{2.5}$ was 8.0 and $8.8 \mu \mathrm{g} / \mathrm{m}^{3}$ for Exposure 2 and Exposure 3 respectively, about 10-fold higher than that of ambient air with $0.8 \mu \mathrm{g} / \mathrm{m}^{3}$ for both exposure periods (Figure 1B). Mean organ carbon and elemental carbon concentrations in the $\mathrm{PM}_{2.5}$ for Exposure 3 were $11.5 \pm 5.3 \mu \mathrm{g} / \mathrm{m}^{3}$ and $2.0 \pm 0.7 \mu \mathrm{g} / \mathrm{m}^{3}$ and together represented $18.9 \%$ of concentrated ambient $\mathrm{PM}_{2.5}$ mass.

\section{Exaggeration of IR in KKay mice by $\mathrm{PM}_{2.5}$}

Since KKay mice are well known to develop abnormalities in glucose metabolism and progressive IR over 5-10 weeks [17], we exposed 5-week old KKay mice to $\mathrm{PM}_{2.5}$ for 5 or 8-week periods (Exposure 1) and evaluated them weekly for glucose and insulin measures. No alteration in body weight or food intake was observed during the exposure to $\mathrm{PM}_{2.5}$ (data not shown). An increase in fasting blood glucose was seen within 1-week of exposure to $\mathrm{PM}_{2.5}$, while insulin levels trended upwards, with the highest values after 6week of exposure and significant differences between the two groups at the 3- and 8-week time-points (Figure 2A). Corresponding homeostasis model assessment of the IR index (HOMA-IR) levels were significantly different at the 1-, 3- and 8-week time-points (Figure 2A).

$\mathrm{PM}_{2.5}$ exposure induces inflammation in hypothalamus of KKay mice

Air pollution has been previously shown to cause CNS inflammation, oxidative stress and pathological alterations such as reactive gliosis $[18,19]$. Our group has reported that long term exposure to $\mathrm{PM}_{2.5}$ over 10 months results in hippocampal pro-inflammatory cytokine expression [20]. Although hypothalamic inflammation is well-documented in models of diet-induced obesity $[10,15,21]$, its role as a potential mediator of altered energy and glucose homeostasis in response to air-pollution has not been explored. To address this question, we examined mRNA encoding inflammatory mediators, including cytokines (IL-6, TNF $\alpha$ ), Suppressor of cytokine signaling 3 (SOCS-3), components of the NFKB pathway (IKK $\beta$ and $I \kappa B$ ), and microglia/ macrophage (MAC1). In the hypothalamus of mice exposed to $\mathrm{PM}_{2.5}$, TNF $\alpha$ and IL-6 expression was elevated after 5-week of exposure to $\mathrm{PM}_{2.5}$ as compared to FA (Figure 2B). Longer duration (8-week) exposure to $\mathrm{PM}_{2.5}$ elevated TNF $\alpha$ and IL- 6 expression, as well as significantly increased IKK $\beta$ expression. There was no difference in the mRNA levels of other genes (Figure 2B). These results suggest that even short-term exposure of a few weeks is sufficient to induce increases in cytokine expression in the medial basal hypothalamus. To further understand the mechanisms responsible for inflammation, we assessed the levels of oxidized 1-palmitoyl-2-arachidonoyl-snglycero-3-phosphocholine (oxPAPC), a prototypic biologically active oxidized phospholipid in the brains of mice exposed to $\mathrm{PM}_{2.5}$ and compared these to FA exposed mice. Ox-PAPC has been previously shown by us and others to activate $\mathrm{NF}_{\kappa} \mathrm{B}$ pathways via toll-like receptor pathways [22,23]. The level of oxPAPC was elevated in $\mathrm{PM}_{2.5}$ exposed mice compared to controls (286054 vs. 180579 arbitrary units). When expressed as a \% of PAPC, the $\mathrm{PM}_{2.5}$ exposed animals demonstrated a 2-fold increase in ox-PAPC/PAPC ratio compared to FA exposed mice (Figure 3).
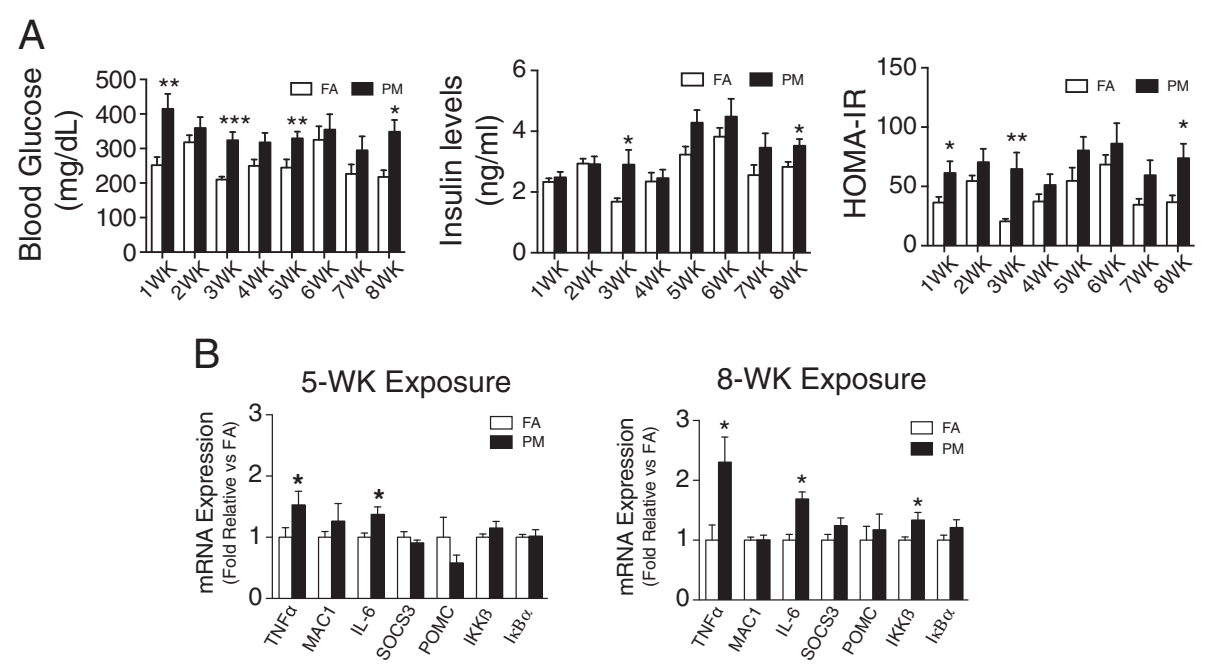

Figure 2 Effect of $\mathbf{P M}_{\mathbf{2 . 5}}$ exposure on glucose homeostasis and hypothalamic inflammation in KKay mice. A, Blood glucose, insulin levels and the HOMA-IR after 6-hr fasting during 8 wks of PM $_{2.5}$ exposure. B, mRNA levels of inflammation mediators in hypothalamus after 5 wks or 8 wks $P M_{2.5}$ exposure. ${ }^{*} P<0.05,{ }^{*} P<0.01,{ }^{* *} P<0.001$ compared to respective FA group. $\mathrm{n}=6$-8 per group. 


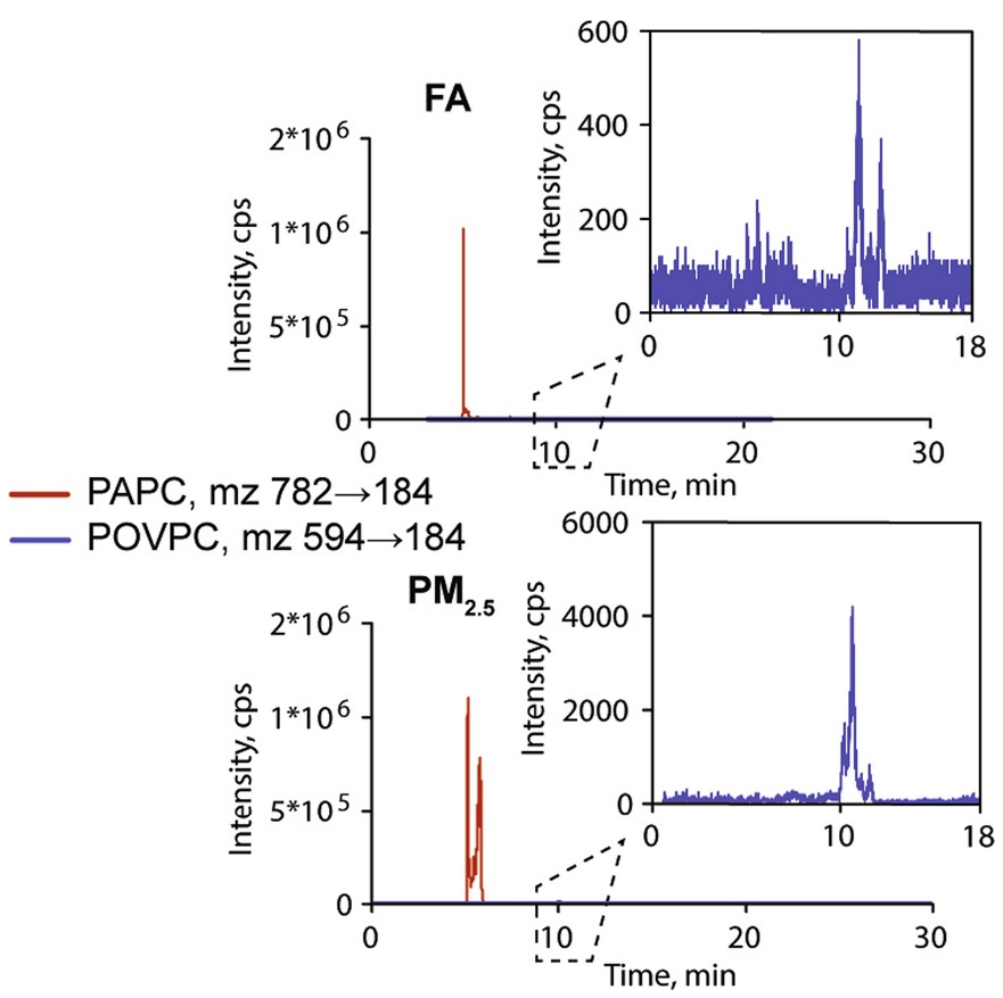

Figure 3 Representative LC-MS chromatograms showing effect of $\mathrm{PM}_{2.5}$ exposure on oxidized PAPC in brain of mice. Lipid extracts from brain of mice exposed to FA or $\mathrm{PM}_{2.5}$ were analyzed by HPLC with positive electrospray ionization mass spectrometry operating in multiple reaction monitoring mode.

\section{ICV infliximab effects on $\mathrm{PM}_{2.5}$-mediated effects on metabolism parameters}

Based on the increased hypothalamic TNF $\alpha$ expression in $\mathrm{PM}_{2.5}$ mice and observations that this may contribute to changes in peripheral inflammation including brown adipose tissue dysfunction [24], we hypothesized that TNF $\alpha$ antagonism may restore peripheral glucose intolerance and altered thermogenesis following $\mathrm{PM}_{2.5}$ exposure. Mice at age of 5 -week were continuously administered infliximab $(0.2 \mu \mathrm{g} /$ day $)$ or artificial cerebrospinal fluid (aCSF) through a minipump connected to a cannula directed at the lateral ventricle. Minipumps were implanted 1 day prior to initiation of either $\mathrm{PM}_{2.5}$ or FA exposure (Exposure 2, Figure 1B). As shown in Figure 4A, intracerebroventricular (ICV) infliximab did not influence peripheral glycemia or insulin tolerance in response to $\mathrm{PM}_{2.5}$ exposure; neither did body temperature, body weight differ between groups (Figure 4B-4C). However food intake was lowered in the PM-Inflix group compared to PM-CON both during the exposure period (Figure 4D) or after the exposure period (Figure 4E).

When analyzing the energy parameters, we used two different analytical strategies as detailed in the Methods. In the first analysis, we used the average measure for each index over time for each mouse and used linear regression. Using this approach no significant difference in $\mathrm{O}_{2}$ consumption, $\mathrm{CO}_{2}$ production, respiratory exchanging ratio (RER) or heat production was observed in response to $\mathrm{PM}_{2.5}$ exposure (Table 1). However, infliximab treatment inhibited heat production in $\mathrm{PM}_{2.5}$ inhaled mice regardless of phase of day. Using repeated measures analysis (adjusting for time), much more significant differences were found. Although only $\mathrm{O}_{2}$ consumption and $\mathrm{CO}_{2}$ production were inhibited in response to $\mathrm{PM}_{2.5}$ inhalation when the data for the entire day were used, $\mathrm{PM}_{2.5}$ inhalation additionally inhibited heat generation during the dark phase (Table 1). These results indicate a consistency of effect of $\mathrm{PM}_{2.5}$ and additionally that metabolism itself displays circadian variation with a higher activity during the dark phase and lower activity during light phase for rodents. Infliximab treatment significantly impaired energy homeostasis, as evidenced by further decreases in $\mathrm{O}_{2}$ consumption, $\mathrm{CO}_{2}$ production, $\mathrm{RER}$, and heat generation in infliximab-treated mice compared to controls (Table 1).

\section{Central IKK $\beta$ inhibition prevents $\mathrm{PM}_{2.5}$-induced disruption of metabolism}

To determine whether upregulated hypothalamic IKK-NF$\mathrm{kB}$ pathway contributes to $\mathrm{PM}_{2.5}$-exaggarated $\mathrm{IR}$, we continuously administered IMD-0354, a pharmacological inhibitor of IKK $\beta$ (IKK2) through a minipump connected to a cannula directed at the lateral ventricle in the same way 

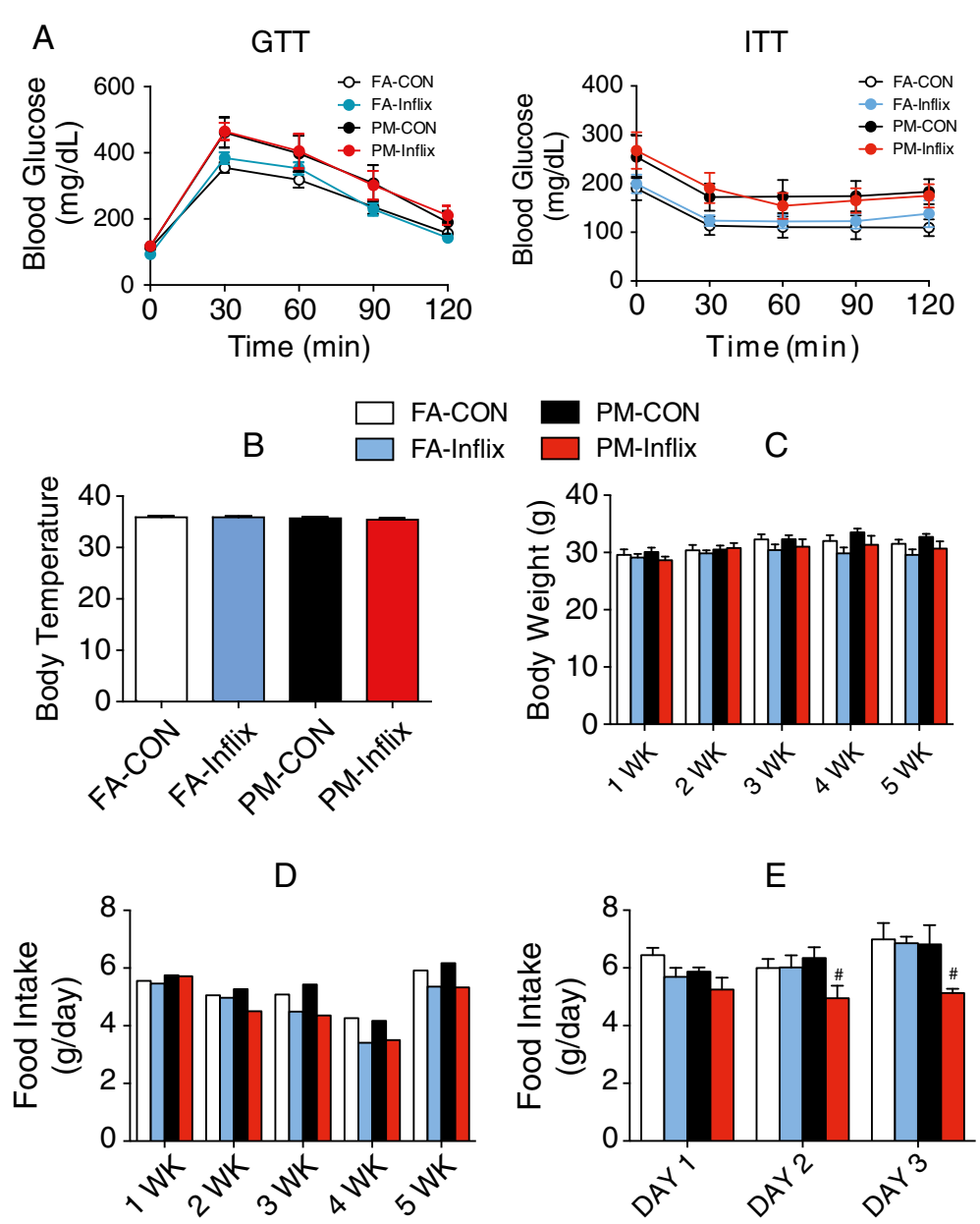

Figure 4 Metabolism response to intracerebroventricular infusion of Infliximab in KKay mice exposed to $\mathrm{PM}_{2.5}$. $\mathbf{A}, \mathrm{GTT}$ and ITT of PM 2.5 exposed KKay mice after 5-week treatment with TNFa antibody. B, Average rectal temperatures for mice by the end of 5-week $\mathrm{PM}_{2.5}$ exposure. C, Body weight of mice during 5-week $\mathrm{PM}_{2.5}$ exposure. D, Average daily food consumption during (D) or after (E) 5-week $\mathrm{PM}_{2.5}$ exposure. $P<0.05$ when compared with PM-CON group.

as Infliximab treatment. Minipumps were implanted 1 day prior to initiation of either $\mathrm{PM}_{2.5}$ or FA exposure for 4 weeks (Exposure 3, Figure 1). Consistent with the results from "exposure 1", $\mathrm{PM}_{2.5}$ induced abnormal glucose tolerance and attenuation of whole-body insulin sensitivity, which were normalized with IMD-0354 treatment (Figure 5A). This effect was $\mathrm{PM}_{2.5}$ dependent, as IMD-0354 did not further improve these parameters in the FA group (Figure 5A). No other difference was shown either in body weight or in food intake during the exposure period between groups except for an increase in body weight after 4 weeks $\mathrm{PM}_{2.5}$ exposure (Figure $5 \mathrm{~B}-\mathrm{C}$ ). Taken together, these results suggest that central IKK $\beta$ inhibition prevents $\mathrm{PM}_{2.5}$-induced abnormalities in glucose/insulin homeostasis.

To examine whether central IKK $\beta$ Inhibition could improve $\mathrm{PM}_{2.5}$-induced impairment of energy metabolism, we measured $\mathrm{O}_{2}$ consumption, $\mathrm{CO}_{2}$ production, RER and heat production and analyzed the data with two analytical strategies. When repeated measures analysis was applied, $\mathrm{PM}_{2.5}$ inhalation inhibited energy metabolism, reflected by decreased $\mathrm{O}_{2}$ consumption, $\mathrm{CO}_{2}$ production and heat generation, both in the whole day phase and in the dark Phase (Figure 6A,B,D). As expected, ICV IMD-0354 normalized the energy metabolism, evidenced by restoration of these parameters $\left(\mathrm{O}_{2}\right.$ consumption, $\mathrm{CO}_{2}$ production heat generation both in the whole day phase and in the dark phase) and further increase in RER in the dark phase, compared with $\mathrm{PM}_{2.5}$-exposed mice administered vehicle (Figure 6 and Table 2). When the analysis of average over time followed by linear regression was applied, $\mathrm{O}_{2}$ consumption, $\mathrm{CO}_{2}$ production and heat generation were all inhibited in response to $\mathrm{PM}_{2.5}$ inhalation only during the day but not the dark period (Figure 6A,B,D). No significant difference was observed between IMD-0354 treated groups and their respective controls (Figure 6, Table 2). 
Table 1 Energy metabolism response to intracerebroventricular infusion of infliximab in KKay mice exposed to $\mathrm{PM}_{2.5}$

\begin{tabular}{|c|c|c|c|c|c|c|c|c|}
\hline \multirow[t]{2}{*}{ Phase } & \multirow{2}{*}{$\begin{array}{l}\text { Measured } \\
\text { index }\end{array}$} & \multirow[t]{2}{*}{ Method } & \multicolumn{3}{|c|}{ FA-CON vs PM-CON } & \multicolumn{3}{|c|}{ PM-CON vs PM-Inflix } \\
\hline & & & Estimate & SE & p-value & Estimate & SE & $\mathrm{p}$-value \\
\hline \multirow[t]{8}{*}{ Light + Dark } & \multirow[t]{2}{*}{$\mathrm{O}_{2}$} & Avg & -193.125 & 170.601 & 0.270 & -182.738 & 170.601 & 0.296 \\
\hline & & $\mathrm{RM}$ & -171.714 & 66.509 & 0.010 & -184.556 & 66.509 & 0.006 \\
\hline & \multirow[t]{2}{*}{$\mathrm{CO}_{2}$} & Avg & -186.684 & 197.569 & 0.355 & -248.623 & 197.569 & 0.222 \\
\hline & & $\mathrm{RM}$ & -159.923 & 79.478 & 0.044 & -248.577 & 79.478 & 0.002 \\
\hline & \multirow[t]{2}{*}{ RER } & Avg & -0.001 & 0.015 & 0.969 & -0.025 & 0.015 & 0.113 \\
\hline & & $\mathrm{RM}$ & 0.001 & 0.008 & 0.899 & -0.025 & 0.008 & 0.003 \\
\hline & \multirow[t]{2}{*}{ Heat } & Avg & -0.020 & 0.033 & 0.548 & -0.076 & 0.033 & 0.030 \\
\hline & & $\mathrm{RM}$ & -0.016 & 0.012 & 0.204 & -0.078 & 0.012 & 0.000 \\
\hline \multirow[t]{8}{*}{ Dark } & \multirow[t]{2}{*}{$\mathrm{O}_{2}$} & Avg & -272.695 & 195.576 & 0.178 & -186.257 & 195.576 & 0.352 \\
\hline & & $\mathrm{RM}$ & -278.074 & 85.804 & 0.001 & -186.729 & 85.804 & 0.030 \\
\hline & \multirow[t]{2}{*}{$\mathrm{CO}_{2}$} & Avg & -273.400 & 234.828 & 0.257 & -289.425 & 234.828 & 0.231 \\
\hline & & $\mathrm{RM}$ & -280.245 & 106.432 & 0.009 & -287.488 & 106.432 & 0.007 \\
\hline & \multirow[t]{2}{*}{ RER } & Avg & -0.002 & 0.019 & 0.901 & -0.037 & 0.019 & 0.062 \\
\hline & & $\mathrm{RM}$ & -0.003 & 0.010 & 0.753 & -0.036 & 0.010 & 0.000 \\
\hline & \multirow[t]{2}{*}{ Heat } & Avg & -0.035 & 0.035 & 0.338 & -0.079 & 0.035 & 0.036 \\
\hline & & $\mathrm{RM}$ & -0.036 & 0.016 & 0.022 & -0.079 & 0.016 & 0.000 \\
\hline
\end{tabular}

$\mathrm{O}_{2}$ consumption, $\mathrm{CO}_{2}$ production, RER and heat production of mice measured by indirect calorimetry over a 24 hrs period (from 10:00 am to $10: 00$ am the next day) after 5-week $\mathrm{PM}_{2.5}$ exposure. $\mathrm{n}=6$.

$A v g=$ analysis performed based on mice averages over cycles. Covariates in the model include PM exposure, treatment group, and the interaction between PM and treatment group.

$R M=$ analysis with repeated measurements. The correlation structure within mice was assumed to be autoregressive-1. Covariates in the model include PM, treatment group, $\mathrm{PM} \times$ treatment interaction, and time.

Mean model using averages over cycles (Avg): $E(Y)=b 0+b 1 P M+b 2$ Trt $+b 3$ PM*Trt.

Mean model using repeated measures data $(R M): E(Y+b 1 P)=b 0 M+b 2$ Trt $+b 3 P^{*} T r t+b 4 c y c l e$.

Covariance structure: autoregressive- 1 .
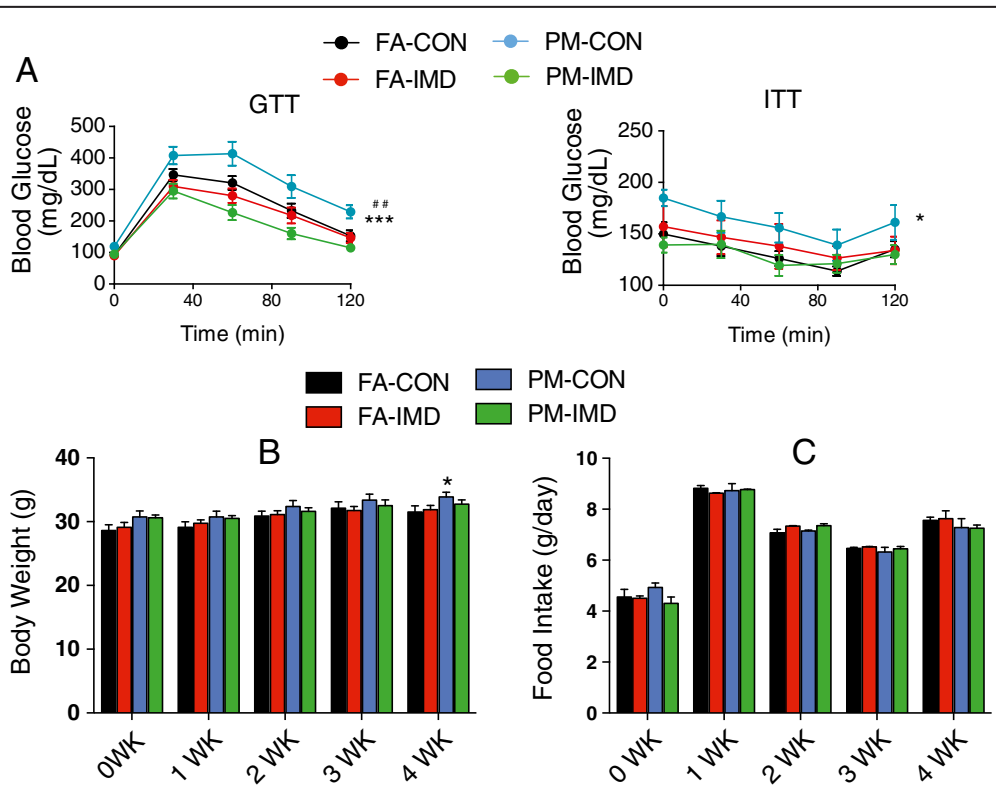

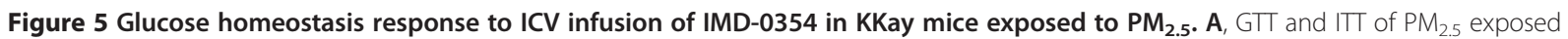
KKay mice after 4-week treatment with IMD-0354. B, Body weight during the 4-week of PM 2.5 exposure and IKK $\beta$ inhibitor treatment. C, Food intake during the 4-week of $\mathrm{PM}_{2.5}$ exposure and IKK 3 inhibitor treatment. ${ }^{*} P<0.05$, ${ }^{* * *} P<0.001$ compared to FA-CON group; \#\#P<0.01 when compared PM-IMD group with PM-CON group. $n=6-8$ per group. 

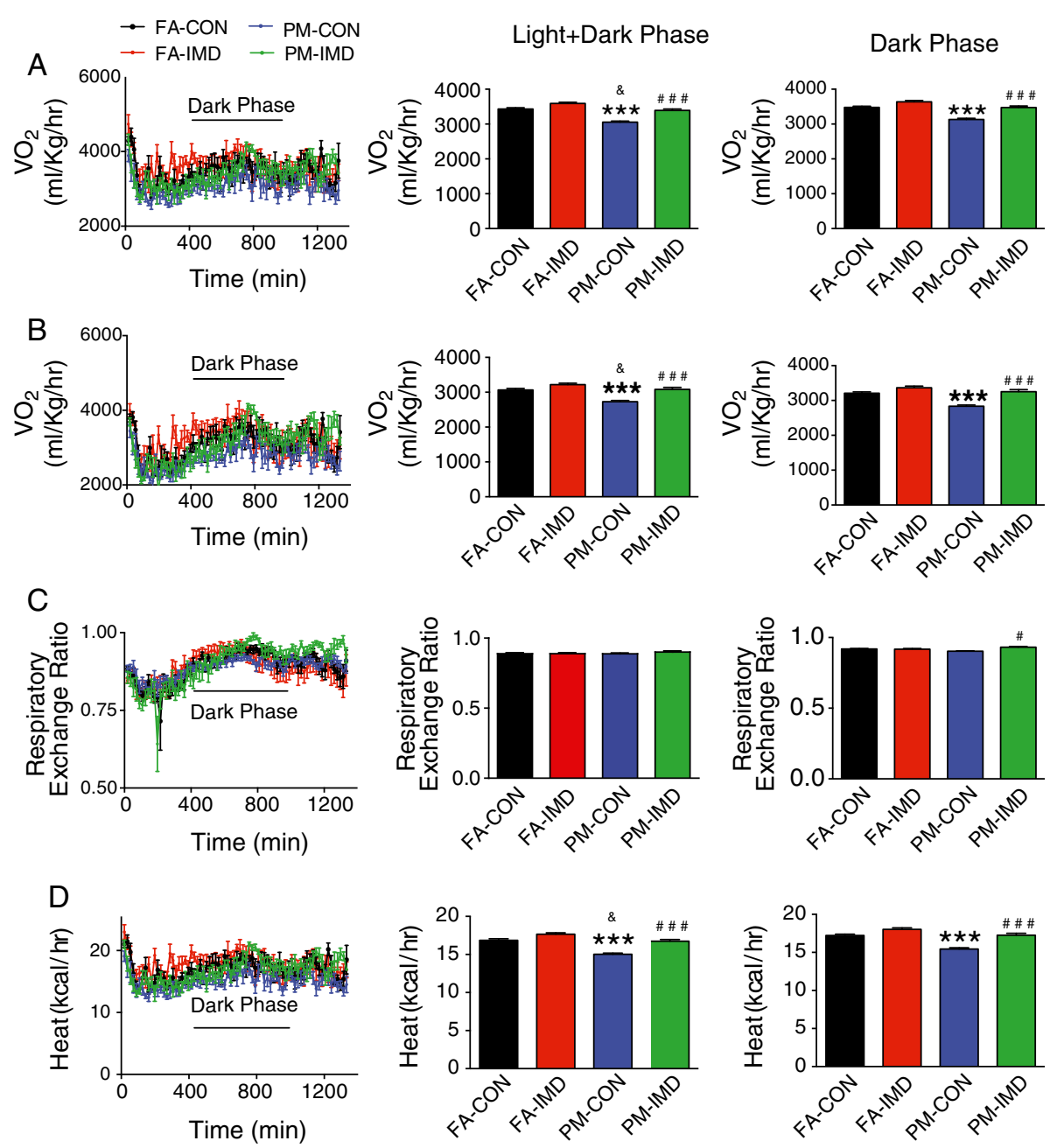

Figure 6 Energy metabolism response to ICV infusion of IMD-0354 in KKay mice exposed to $\mathbf{P M}_{\mathbf{2 . 5}} \cdot \mathrm{O}_{2}$ consumption (A), $\mathrm{CO}_{2}$ production (B), respiratory exchanging ratio (C) and heat production (D) of mice measured by indirect calorimetry over a 24 hrs period (from 10:00 am to 10:00 am the next day) after 4 wks of $\mathrm{PM}_{2.5}$ exposure and IKK $\beta$ inhibitor treatment. When RM (repeated measures adjusting for time) analysis was applied: ${ }^{* *} P<0.001$ compared to FA-CON group; $\# P<0.05$, \#\#\# < 0.001 when compared PM-IMD group with PM-CON group. When Avg (the average over time followed by linear regression) was applied, \&P<0.05 compared to FA-CON group. $n=6$ per group.

\section{Central IKK $\beta$ inhibition ameliorates $\mathrm{PM}_{2.5}$-induced peripheral inflammation}

We next investigated the effect of central IKK $\beta$ inhibition on peripheral inflammation induced by $\mathrm{PM}_{2.5}$ exposure. In the present study, we defined monocytes as side scatter-high, forward scatter-low cells expressing the myeloid antigen 7/4 (high populations) and high levels of CD11b but low for the neutrophil marker Gr-1 (Ly6G), which corresponds to Ly6 $\mathrm{C}^{\mathrm{hi}}$ monocytes and represents the inflammatory subtype $[23,25,26]$. We noted a clear trend $(\mathrm{P}=0.0518)$ of increase in circulating $\mathrm{CD}_{11 \mathrm{~b}}{ }^{+} \mathrm{Gr}-$ $1^{\text {low }} 7 / 4^{\text {hi }}$ cells, the inflammatory subtype in response to $\mathrm{PM}_{2.5}$ exposure. The levels of $\mathrm{CD} 11 \mathrm{~b}^{+} \mathrm{Gr}-1^{\text {low }} 7 / 4^{\text {hi }}$ in circulation were reduced in mice treated with IMD-0354 ICV (Figure 7A).
$\mathrm{F} 4 / 80^{+} \mathrm{CD} 11 \mathrm{c}^{+}$is a macrophages marker and these cells have been demonstrated to play a pathophysiological role in high-fat diet-induced obesity [27-31]. F4/ $80^{+} / \mathrm{CD}_{11 \mathrm{c}^{+}}$cells in visceral adipose tissue (VAT) were markedly higher in response to $\mathrm{PM}_{2.5}$ exposure, with the increase being attenuated by IMD-0354 treatment (Figure 7B). Together with data demonstrating that $\mathrm{PM}_{2.5}$-mediated monocytes infiltration into VAT is CCR2 dependent [32], these results suggest mechanisms similar to those involved in diet mediated aggravation of the VAT infiltration by monocytes via CCR2 dependent pathways [29]. These results indicate that peripheral inflammation in blood and adipose tissue in response to $\mathrm{PM}_{2.5}$ is dependent on CNS inflammation to a considerable degree. 
Table 2 Energy metabolism response to intracerebroventricular infusion of IMD 0354 in KKay mice exposed to PM 2.5

\begin{tabular}{|c|c|c|c|c|c|c|c|c|}
\hline \multirow[t]{2}{*}{ Phase } & \multirow{2}{*}{$\begin{array}{l}\text { Measured } \\
\text { index }\end{array}$} & \multirow[t]{2}{*}{ Method } & \multicolumn{3}{|c|}{ FA-CON vs PM-CON } & \multicolumn{3}{|c|}{ PM-CON vs PM-IMD } \\
\hline & & & Estimate & SE & $p$-value & Estimate & SE & $\mathrm{p}$-value \\
\hline \multirow[t]{8}{*}{ Light + Dark } & \multirow[t]{2}{*}{$\mathrm{O}_{2}$} & Avg & -370.927 & 149.129 & 0.032 & 331.662 & 167.254 & 0.061 \\
\hline & & $\mathrm{RM}$ & -371.022 & 59.968 & 0.000 & 335.500 & 64.236 & 0.000 \\
\hline & \multirow[t]{2}{*}{$\mathrm{CO}_{2}$} & Avg & -333.440 & 127.020 & 0.025 & 347.582 & 181.272 & 0.070 \\
\hline & & $\mathrm{RM}$ & -332.649 & 62.399 & 0.000 & 351.053 & 76.737 & 0.000 \\
\hline & \multirow[t]{2}{*}{ RER } & Avg & 0.000 & 0.009 & 0.985 & 0.011 & 0.016 & 0.473 \\
\hline & & RM & 0.000 & 0.006 & 0.989 & 0.011 & 0.009 & 0.205 \\
\hline & \multirow[t]{2}{*}{ Heat } & Avg & -1.826 & 0.722 & 0.030 & 1.694 & 0.855 & 0.061 \\
\hline & & $\mathrm{RM}$ & -1.825 & 0.303 & 0.000 & 1.712 & 0.336 & 0.000 \\
\hline \multirow[t]{8}{*}{ Dark } & \multirow[t]{2}{*}{$\mathrm{O}_{2}$} & Avg & -346.732 & 185.106 & 0.076 & 340.550 & 185.106 & 0.081 \\
\hline & & RM & -340.496 & 82.903 & 0.000 & 336.695 & 82.903 & 0.000 \\
\hline & \multirow[t]{2}{*}{$\mathrm{CO}_{2}$} & Avg & -372.246 & 209.234 & 0.090 & 414.139 & 209.234 & 0.062 \\
\hline & & RM & -359.378 & 97.723 & 0.000 & 406.893 & 97.723 & 0.000 \\
\hline & \multirow[t]{2}{*}{ RER } & Avg & -0.016 & 0.017 & 0.360 & 0.028 & 0.017 & 0.117 \\
\hline & & $\mathrm{RM}$ & -0.012 & 0.010 & 0.248 & 0.026 & 0.010 & 0.012 \\
\hline & \multirow[t]{2}{*}{ Heat } & Avg & -1.781 & 0.958 & 0.078 & 1.809 & 0.958 & 0.073 \\
\hline & & $\mathrm{RM}$ & -1.743 & 0.433 & 0.000 & 1.786 & 0.433 & 0.000 \\
\hline
\end{tabular}

$\mathrm{O}_{2}$ consumption, $\mathrm{CO}_{2}$ production, $\mathrm{RER}$ and heat production of mice measured by indirect calorimetry over a 24 hrs period (from 10:00 am to 10:00 am the next day) after 5-week $\mathrm{PM}_{2.5}$ exposure. $\mathrm{n}=6$.

$\mathrm{Avg}=$ analysis performed based on mice averages over cycles. Covariates in the model include PM exposure, treatment group, and the interaction between PM and treatment group.

$\mathrm{RM}=$ analysis with repeated measurements. The correlation structure within mice was assumed to be autoregressive-1. Covariates in the model include PM, treatment group, PM $x$ treatment interaction, and time.

Mean model using averages over cycles (Avg): $\mathrm{E}(\mathrm{Y})=\mathrm{b} 0+\mathrm{b} 1 \mathrm{PM}+\mathrm{b} 2 \mathrm{Trt}+\mathrm{b} 3 \mathrm{PM} * \mathrm{Trt}$

Mean model using repeated measures data $(R M): E(Y)=b 0+b 1 P M+b 2$ Trt $+b 3 P^{*} M^{*}$ Trt + b4cycle.

Covariance structure: autoregressive-1.

\section{Central IKK $\beta$ inhibition suppresses $\mathrm{PM}_{2.5}$-induced hypothalamic inflammation}

As depicted in Figure 8A, IMD-0354 reduced IL-6 and IKK $\beta$ expression, both of which were up-regulated by $\mathrm{PM}_{2.5}$ exposure, but had no effect on TNF $\alpha$ and ІкB expression. Reactive gliosis, identified by the recruitment, activation, and proliferation of glial cells, such as astrocytes, NG2 cells, and microglia, in the arcuate nucleus of the hypothalamus, has been associated with changes in metabolic homeostasis [13]. Thus, we investigated the effects of $\mathrm{PM}_{2.5}$ exposure and IKK $\beta$ inhibition on microglia and astrocyte reactivity in the arcuate nucleus of the hypothalamus. Using anti-Iba1 (ionized calcium binding adaptor molecule 1), a microglia-specific cytoplasmic marker [33], we found a $20 \%$ increase in microglial number in the arcuate nucleus of mice exposed to $\mathrm{PM}_{2.5}$ compared to FA (Figure 8B). Additionally, microglia from $\mathrm{PM}_{2.5}$ mice were larger with a more activated morphology (Figure 8C). Central IMD-0354 infusion restored both the number and size of microglia in response to $\mathrm{PM}_{2.5}$ (Figure $8 \mathrm{~B}-\mathrm{C}$ ). The effect of $\mathrm{PM}_{2.5}$ on astrocytes was assessed with GFAP immunostaining. Astrocytes are abundant throughout the CNS and were apparent in the arcuate nucleus of all groups. The intensity of GFAP staining which was elevated among $\mathrm{PM}_{2.5}$ mice was prevented by treatment with the IKK $\beta$ inhibitor (Figure 9). Chronic high fat feeding results in prolonged inflammatory responses in the CNS, which can cause loss of sensing in proopiomelanocortin (POMC) neurons [34]. POMC neurons are critical components of the network regulating energy balance in mammals and loss of POMC neurons is associated with development of metabolic syndrome [35]. Therefore we examined evidence of POMC neuronal loss in the hypothalamus; however, neither $\mathrm{PM}_{2.5}$ exposure nor drug treatment affected POMC number (data not shown, $P>0.05)$.

\section{Discussion}

In this paper we demonstrate $\mathrm{PM}_{2.5}$ exposure induces hypothalamic inflammation in a genetically susceptible model of Type II DM. The increased cytokine expression in the hypothalamus was accompanied by evidence of exacerbation of peripheral glycemia and IR. Increased levels of oxidized phospholipids in the brain may represent one possible mechanism that may account for activation of downstream inflammatory pathways. Central IKK $\beta$ inhibition but not TNF $\alpha$ blockade prevented the effects of $\mathrm{PM}_{2.5}$ on glucose tolerance and insulin sensitivity, restored 


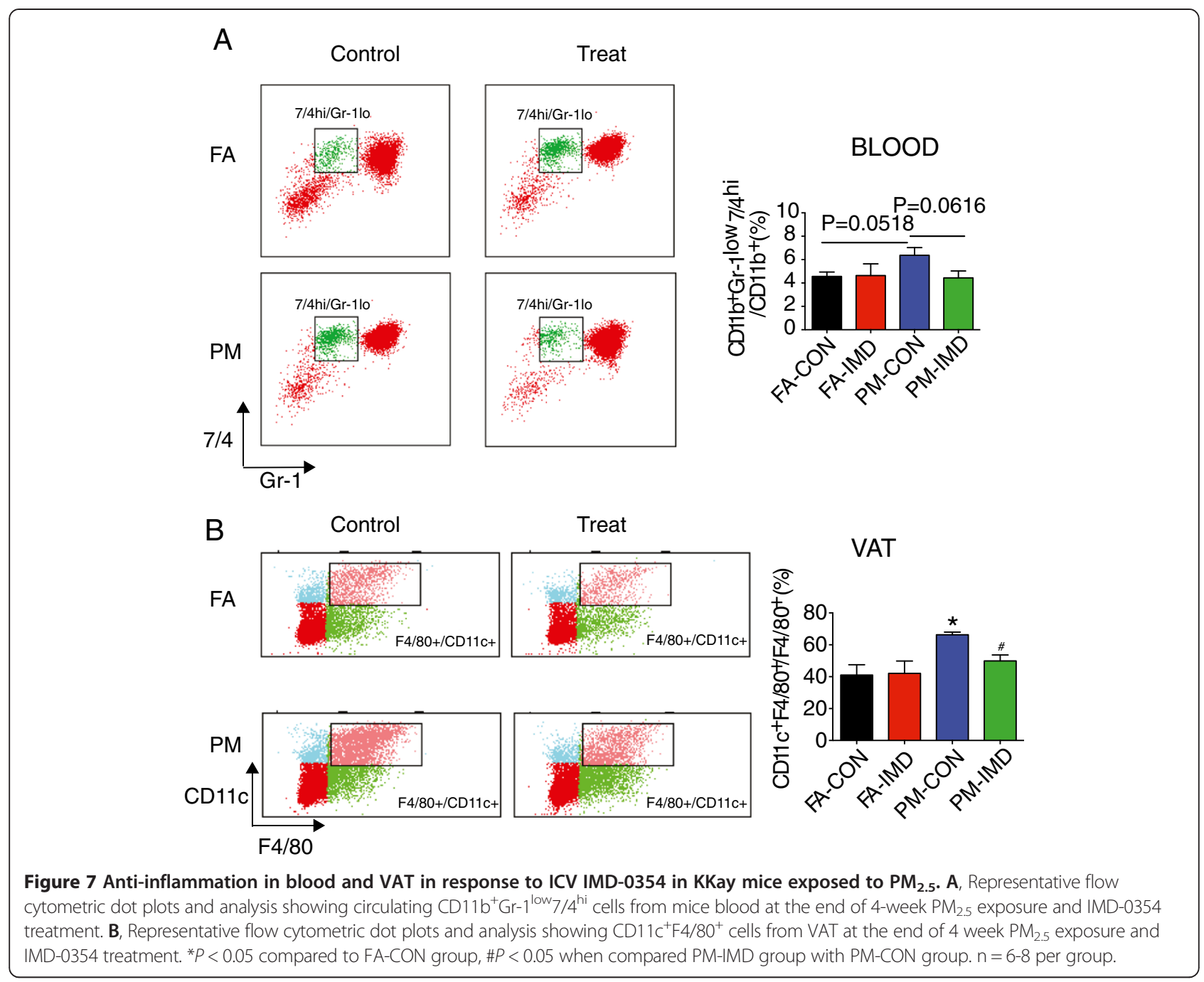

abnormal $\mathrm{O}_{2}$ consumption, $\mathrm{CO}_{2}$ production, heat generation and inhibited the $\mathrm{PM}_{2.5}$-enhanced peripheral inflammation. Importantly, central IKK $\beta$ inhibition effectively reduced IL-6 and reactive gliosis in hypothalamus. In addition, the consistency of the effect regardless of location of exposure (urban in exposure 1 vs. near roadway in exposures 2 and 3) suggests that there may be no significant differences at least within the confines of a large urban area, regardless of proximity to a highway, although our study was not designed to test these differences.

A number of studies have shown that exposure to $\mathrm{PM}_{2.5}$ is associated with, or lead directly to IR, adiposity, plaque destabilization, and adverse cardiovascular events, in which pro-inflammatory and oxidative stress pathways play critical roles [5,36-40]. In rodent models of diet-induced obesity, increased inflammatory signaling in the mediobasal hypothalamus occur early and prior to peripheral inflammation and altered energy homeostasis [12,13,41]. These findings suggest that inflammatory changes in the CNS may mechanistically contribute to the development of obesity and IR [15].

The CNS plays a critical role in energy balance with multiple environmental and internal signals serving as cues to trigger the requisite behavioral and physiological response to maintain energy homeostasis. Considerable progress has been made in elucidating the molecular and cellular pathways, primarily within the hypothalamus and hindbrain. In previous studies, we have demonstrated evidence of CNS inflammation in the hippocampus with long term $\mathrm{PM}_{2.5}$ exposure (10 months) [20]. However, the results in the present study suggest that exposure even over a few weeks is sufficient to induce increase in TNF $\alpha$ and IL-6 and reactive gliosis in the medial basal hypothalamus. In this regard, the hypothalamus may be particularly vulnerable to the effects of diet and environmental signals such as $\mathrm{PM}_{2.5}$ because the blood brain barrier is relatively permeable in this part of the brain.

Our findings may have important implications for potential pathways by which $\mathrm{PM}_{2.5}$ mediate alteration in 


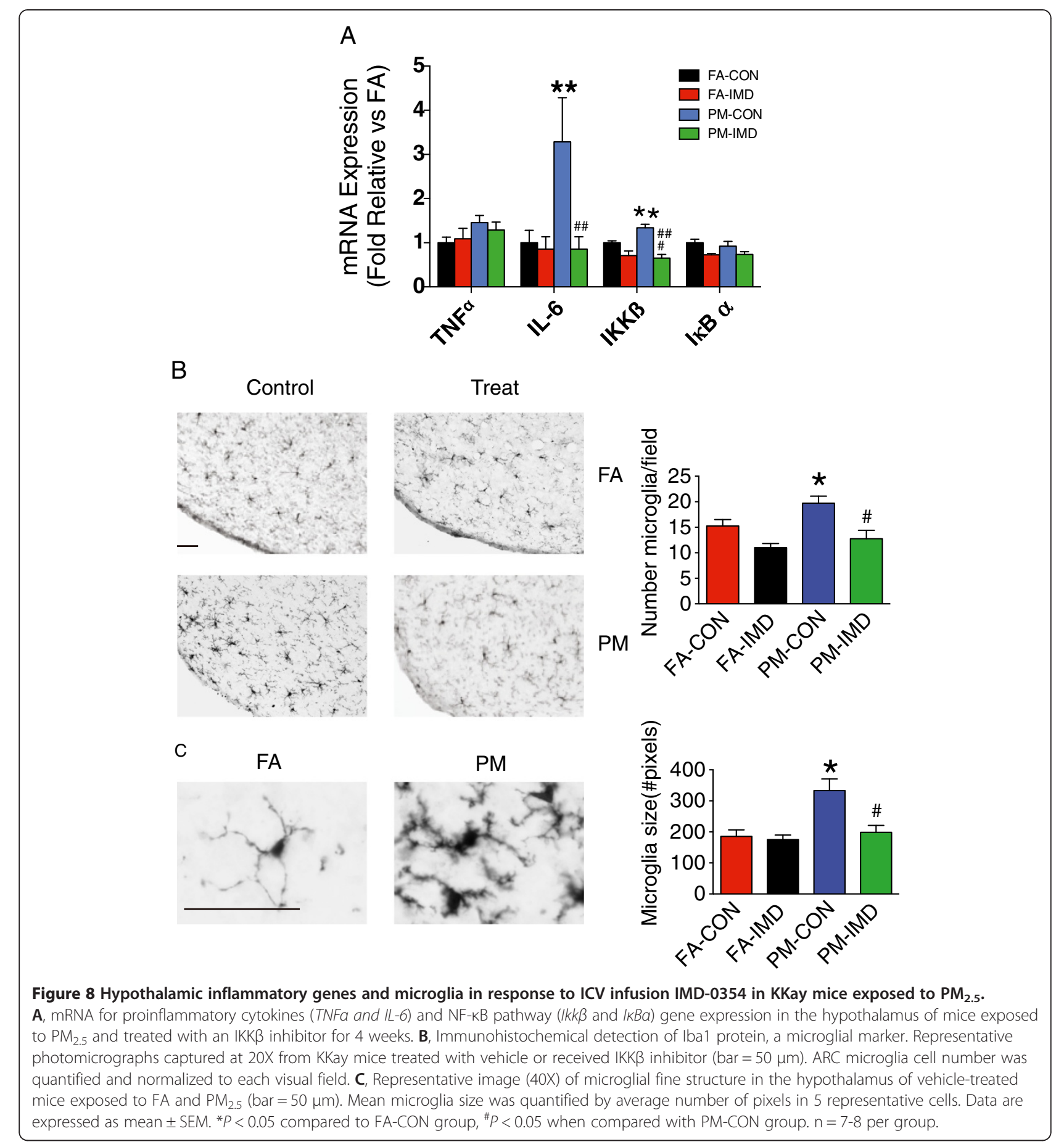

peripheral metabolic dysfunction. Examining inflammation in hypothalamus, even earlier (within the first several days of $\mathrm{PM}_{2.5}$ inhalation), would help to clarify the initiating role of central inflammation in the genesis of IR. $\mathrm{PM}_{2.5}$ has been shown to permeate the CNS via translocation along the olfactory nerve into the olfactory bulb and exert direct effects on CNS inflammation $[19,42]$. Alternatively, $\mathrm{PM}_{2.5}$ exposure may directly affect vagal afferents that may play an important role in modulation of pathways that affect cardiovascular and/or peripheral inflammatory responses [43]. As alterations in hypothalamic signaling induced by overnutrition (particularly hypothalamic leptin resistance) has been demonstrated to alter sympathetic outflow, this mechanism could also help couple sympathetic activation with systemic IR [44-46]. In addition, neurotransmitters released through peripheral 
A
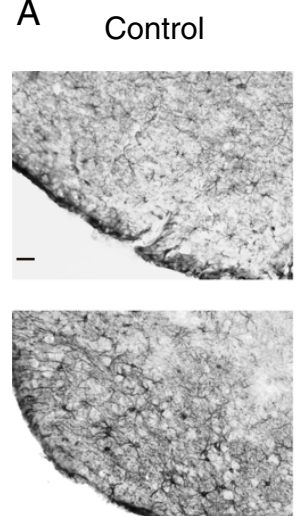

Treat
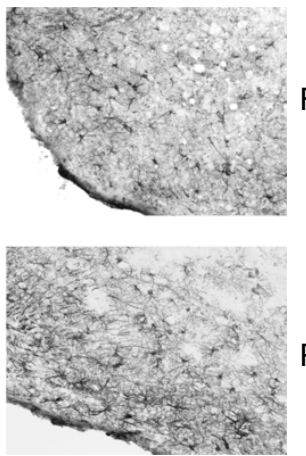

FA

PM
B

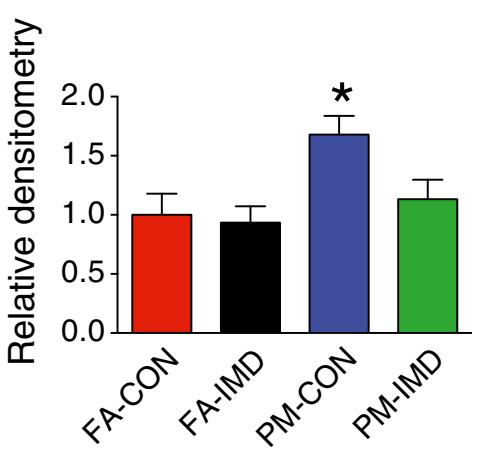

Figure 9 Hypothalamic astrocytes in response to intracerebroventricular infusion of IMD-0354 in KKay mice exposed to $\mathrm{PM}_{2.5}$.

A, Representative images (10X) of astrocytes identified by immunohistochemical detection of GFAP protein in the hypothalamus of $\mathrm{PM}_{2.5}$-exposed mice treated with IKK $\beta$ inhibitor. The bar $=50 \mu \mathrm{m}$. B, Quantification of GFAP staining intensity in the ARC. Data are expressed as mean $\pm S E M,{ }^{*} P<0.05$ when compared with FA-CON group.

and autonomic nerves may play an important role in activation of these cells, thus linking the alterations in neural function with peripheral inflammation [47]. However, additional studies are required to characterize the precise pathways.

In light of the importance of hypothalamic TNFo in response to high fat diet [10] and our own results of the increased TNF $\alpha$, we hypothesized that this cytokine may play a role in $\mathrm{PM}_{2.5}$-mediated IR and that its inhibition may prevent progression of IR in the KKay model. However, TNF $\alpha$ blockade at the dosage used in the study did not antagonize the adverse effects of $\mathrm{PM}_{2.5}$ on glucose metabolism and energy homeostasis. Our results are however contrary to reports showing that central TNF $\alpha$ administration reduced the expression of thermogenic proteins in brown adipose tissue and skeletal muscle, effects that were blunted in TNF $\alpha$ receptor knockout mice $[16,48]$. Depending on its local concentrations, TNF $\alpha$ can exert dual functions in the hypothalamus, being catabolic at high and anabolic at low concentrations. Consistent with these divergent effects on energy metabolism, TNF $\alpha$ levels in obese animals are higher than that in control rats but significantly lower than that in tumor-bearing rats. These effects were accompanied by inhibition of feeding/anorexia in tumorbearing, and increase in feeding (orexigenic effect) in obese animals respectively [16]. It is attractive to propose that the effect of infliximab, is a reflection of the paradoxical, concentration dependent effect of TNF $\alpha$ on metabolism.

In contrast, antagonism of IKK $\beta$, the enzyme regulating cytokine production, completely corrected $\mathrm{PM}_{2.5}$-induced dysfunction of glucose homeostasis. These effects are consistent with a role for $\mathrm{NFKB}$ activation via toll-like receptor mechanisms in response to oxPAPC generated by $\mathrm{PM}_{2.5}$ as previously demonstrated by us [23]. This mechanism while applicable to $\mathrm{PM}_{2.5}$, may potentially apply to other situations including high-fat feeding. Consistent with this, Zhang et al. have previously demonstrated increased expression and activation of hypothalamic IKK $\beta / \mathrm{NF}-\mathrm{KB}$ in obesity, both in leptin-deficient ob/ob mice fed a normal chow and in high fat diet-induced obese animals [15]. These results suggest that hypothalamic IKK $\beta$ but not TNF $\alpha$ is important in $\mathrm{PM}_{2.5}$-mediated peripheral effects and suggest a role for TLR pathways (at least not TNF $\alpha$ ) pathways in $\mathrm{PM}_{2.5}$ mediated peripheral effects.

Although our results suggest an important role for CNS inflammation via $I K K \beta$ in $\mathrm{PM}_{2.5}$-mediated diabetes development, several questions remain. Firstly, it is not known which cell type(s) are involved in the initiation of $\mathrm{PM}_{2.5}$-induced inflammatory responses in hypothalamus. Although evidence suggests that IKK $\beta / N F-\kappa B$ in specific neuronal populations is critical to high fat diet-induced inflammation and IR, the precise cell type and the role of microglial cells remain unclear [15,49]. Secondly, the specific components of $\mathrm{PM}_{2.5}$ that mediate these effects remain to be defined. We have provided detailed analysis on components such as trace elements in prior studies $[32,50]$ as well as organic carbon fraction in this study (Figure 1). We however submit that source apportionment type analysis is clearly beyond the scope of this paper. Thirdly, we can not exclude direct off target systemic effects with the pharmacological inhibitor of IKK $\beta$ by ICV in the study. To further confirm the hypothesis, targeted deletion of IKK $\beta$, either with direct intra-nuclear injection into the arcuate nucleus of adenovirus expressing dominant negative IKK $\beta$ or cre-recombinase in conditionally expressed models will be required. However, considering that the dose used in the present study (600 ng/day ICV) was about 1,000-fold lower than that used when peripherally administered (10$20 \mathrm{mg} / \mathrm{kg}$ ), it is unlikely that the effects seen in this study are occurring secondary to systemic spill-over [51]. So, 
even there is some "spillover", it is very unlikely to contribute to systemic effects. Fourthly, the precise upstream pathways leading to the activation of IKK $\beta$ and the precise molecular instigators of IKK- $\beta$ activation remain to be determined.

In summary, our results suggest an important role for $\mathrm{PM}_{2.5}$-induced hypothalamic inflammation in modulating susceptibility to Type II DM. Given the importance of air pollution as a mediator of global morbidity and mortality, its continuous and omnipresent nature, even small adverse health associations for individuals may have profound public health implications on a global scale [1,2].

\section{Methods}

\section{Animals and animal care}

KKay mice of 5-week-old or 7-week-old were purchased from Jackson Laboratories (Bar Harbor, Me). All mice were maintained at $21^{\circ} \mathrm{C}$ on a 12 -h light/12-h dark cycle with free access to water and food. The protocols and the use of animals were approved by and in accordance with the Ohio State University Animal Care and Use Committee. The animals were treated humanely and with regard for alleviation of suffering.

\section{Ambient whole-body inhalational protocol and groups}

There were three distinct exposure periods, Exposure 1, Exposure 2, and Exposure 3. During the exposure periods, KKay mice were exposed by inhalation to either FA or concentrated ambient $\mathrm{PM}_{2.5}$ with 2 different exposure systems ("Ohio Air Pollution Exposure System for Interrogation of Systemic Effects") located either at the Ohio State University Laboratory Animal Center (LAC) Facility in Godown Road Columbus (urban exposure facility, not proximal to a major roadway) or at the Polaris Facility (near roadway facility located within $250 \mathrm{~m}$ of a major interstate highway). Exposure 1 was conducted in LAC while Exposure 2 and 3 were conducted in Polaris Facility. For Exposure 1 (mice were exposed for $6 \mathrm{~h} / \mathrm{d}, 5 \mathrm{~d} / \mathrm{wk}$, 5 weeks or 8 weeks. For Exposure 2, mice were treated (ICV) with infliximab or artificial CSF through an implanted ICV catheter (see ICV drug infusion protocol) and exposed for $6 \mathrm{~h} / \mathrm{d}, 5 \mathrm{~d} / \mathrm{wk}$, for 5 weeks. For Exposure 3, mice were treated (ICV) with IMD-0354 or vehicle of DMSO and exposed for $6 \mathrm{~h} / \mathrm{d}, 5 \mathrm{~d} / \mathrm{wk}$, for 4 weeks. For ease of identification, the animal groups were named 5WK-FA, 5WK-PM, 8WK-FA and 8WK-PM during Exposure 1 ( $\mathrm{n}=7$-8/group); FA-CON and PM-CON (ICV with aCSF), FA-Inflix and PM-Inflix (ICV with TNF $\alpha$ antibody, Infliximab, Remicaded), during Exposure 2 ( $n=6 /$ group); FA-CON and PM-CON (ICV with vehicle of DMSO), FA-IMD and PMIMD (ICV with IKK $\beta$ inhibitor, IMD-0354, Sigma) during Exposure 3 ( $\mathrm{n}=8$ for each group). Animal exposure and monitoring of the exposure environment and ambient aerosol were performed as previously described [5,36].

\section{$\mathrm{PM}_{2.5}$ concentration in the exposure chamber}

To calculate exposure mass concentrations of concentrated ambient $\mathrm{PM}_{2.5}$ in the exposure chambers, samples were collected on Teflon filters (PTFE, $37 \mathrm{~mm}, 2 \mu \mathrm{m}$ pore; PALL Life Sciences, Ann Arbor, MI) and weighed before and after sampling in a temperature- and humidity-controlled weighing room using a Mettler Toledo Excellence Plus XP microbalance. Weight gains were used to calculate exposure concentrations.

\section{ICV drug infusion}

A stereotaxic apparatus was used to implant a cannula into the right lateral ventricle of mice anesthetized with $2 \%$ isoflurane in air. Cannula positions were +0.02 posterior and -0.95 lateral to Bregma, extending $2.75 \mathrm{~mm}$ below the skull (Plastics One, Roanoke, VA). The cannula was connected via tubing to an Alzet minipump (Model 1004, Durect, Cupertino, CA) that was implanted subcutaneously in the scapular region and delivered either drugs (Infliximab and IMD 0354) or vehicles, both at a rate of $0.11 \mu \mathrm{L} / \mathrm{h}$. Minipumps were implanted 1 day prior to initiation of either $\mathrm{PM}_{2.5}$ or FA exposure. The infliximab-treated groups received a total of $0.2 \mu \mathrm{g}$ of the antibody, and the IMD0354-treated groups received a total of $600 \mathrm{ng}$ of the inhibitor per day. Cannula placement was verified in tissue used for immunohistochemistry.

\section{Measurements of blood glucose homeostasis and insulin sensitivity}

Before and subsequent to the exposure to FA or $\mathrm{PM}_{2.5}$, mice were fasted overnight and dextrose $(2 \mathrm{mg} / \mathrm{g}$ body weight) was injected intra-peritoneally for intra-peritoneal glucose tolerance testing (IPGTT). Blood sample was collected from the vena caudalis and blood glucose measurement was conducted with an Contour Blood Glucose Meter (Bayer, Mishawaka, IN) at baseline, and 30, 60, 90, and 120 minutes after the dextrose injection. During the exposure period, $6 \mathrm{~h}$-fasting blood glucose was monitored every week, with the same glucose meter as GTT. Insulin levels were determined using an Ultra Sensitive Mouse Insulin ELISA Kit (Crystal Chem Inc., Downers Grove, IL). HOMA-IR were calculated based on $1 \mathrm{mg}$ of insulin as equivalent to $24 \mathrm{IU}$, using the formula HOMA = [fasting insulin concentration $(\mathrm{ng} / \mathrm{ml}) \times 24 \times$ fasting glucose concentration (mg/dl)]/405 [36].

By the end of exposure, insulin sensitivity was measured by the insulin tolerance test (ITT). After 4.5 hours fasting, Insulin $(0.5 \mathrm{U} / \mathrm{kg})$ was administered by intra-peritoneal injection. Blood glucose measurement was conducted in the same way as IPGTT with the same Contour Blood Glucose Meter at baseline, and 30, 60, 90, and 120 minutes after insulin injection. 
Oxygen consumption and heat production measurement

The mice were isolated in a semi-sealed cage, and the inner air was aspirated at a constant volume/min. Oxygen consumption, $\mathrm{CO}_{2}$ production, respiratory exchanging ratio and heat production were measured simultaneously using a computer-controlled, open-circuit Oxymax/CLAMS System (Columbus Instruments, Columbus, $\mathrm{OH}$ ). Each mouse was measured individually in a resting state at $22^{\circ} \mathrm{C}$ in the presence of food and water [52]. Measurements were taken for a 24-h period, including a 12-h light cycle and a 12-h dark cycle. Data were normalized to body weight.

\section{Flow cytometric evaluation of inflammation in blood/tissues}

Visceral adipose tissues from the mice were excised, minced, and digested with collagenase type II, and the SVF isolated as described previously.These cells were centrifuged at $500 \times \mathrm{g}$ for $5 \mathrm{~min}$. Whole blood was centrifuged at $500 \times \mathrm{g}, 4^{\circ} \mathrm{C}$ for $5 \mathrm{~min}$ and plasma was collected. The remaining blood cells and the resulting pellets were resuspended in $1 \mathrm{X}$ red blood cell lysis buffer (Biolegend, San Diego, CA), at room temperature for 3 minutes followed by addition of $1 \mathrm{X}$ PBS and centrifugation. Then, blood cells spleen cells and bone marrow derived cells were stained with anti-CD11b, anti-7/4 and anti-Gr-1, SVFs were stained with anti-CD11c and F4/80, both followed by incubation at room temperature for 45 minutes. Cells were subsequently washed with 1 X PBS and re-suspended in 1\% neutral buffered formalin and run by flow cytometry (BD FACS LSR II $^{\mathrm{IM}}$ flow cytometer, Becton Dickinson, San Jose, CA). Data was analyzed using BD FACS Diva software (Becton Dickinson, San Jose, CA). All antibodies were purchased from Biolegend, Miltenyi Biotec, or BD Bioscience [23,53].

\section{Immunohistochemistry}

Mice were perfused transcardially with ice-cold 0.1 $M$ PBS. Brains were removed, divided at the hemisphere with a sterile razor, and the right hemisphere was fixed overnight in $4 \%$ paraformaldehyde. The half brains were subsequently cyroprotected in $30 \%$ sucrose, frozen in isopentane with dry ice, and stored at $-80^{\circ} \mathrm{C}$. Eighteen $\mu \mathrm{m}$ brain sections were sliced at $-22^{\circ} \mathrm{C}$ using a cryostat, thaw mounted onto Super Frost Plus slides (Fisher, Hampton, NH), and stored at $-20^{\circ} \mathrm{C}$. The sections were rinsed in PBS and blocked with $4 \%$ BSA in PBS + Triton-X (TX) for $1 \mathrm{~h}$ with constant agitation. Alternate slides were incubated overnight with rabbit anti-Iba-1 (1:1000, Wako Chemicals, Richmond, VA), rabbit anti-GFAP (1:1000, abcam, Cambridge, MA) or rabbit antiPOMC (1:4000; Pheonix Pharmaceuticals, Burligame, CA). After PBS rinses the slides were subsequently incubated for $1 \mathrm{~h}$ at room temperature with biotinylated goat-anti-rabbit 1:1000 in PBS + TX (Vector Laboratories, Burligame, CA). Sections were then quenched for $20 \mathrm{~min}$ in methanol containing $0.3 \%$ hydrogen peroxide. After washing with
PBS, sections were incubated for $1 \mathrm{~h}$ with avidin-biotin complex (ABC Elite kit, Vector laboratories). After rinses the sections were developed in diaminobenzidine for $\sim 2 \mathrm{~min}$ (Sigma, D4168), rinsed, and immediately dehydrated and coverslipped with Permount. Images were captured on a Nikon E800 microscope and analyzed using Image J software $(\mathrm{NIH})$ to determine immunoreactive regions. For the GFAP densitometry analysis and microglia counts 2 sections were used per mouse and averaged to generate a single value. To establish the relative microglial size, 6 representative microglia were selected per animal for pixel count and also averaged to generate a single value.

\section{Quantitative RT-PCR}

RT-PCR was performed using RNA extracted from hypothalamus of the experimental mice. After brains were removed, the left brain hemisphere was placed in RNAlater. The hypothalamus was subsequently removed and total RNA was extracted using a homogenizer (Ultra-Turrax T8, IKAWorks, Wilmington, NC) and an RNeasy Mini Kit (Qiagen, Austin, TX) according to manufacturer instructions. RNA was then reverse transcribed into cDNA with M-MLV Reverse Transcriptase enzyme (Invitrogen, Carlsbad, CA). Gene expression for TNFa, IL6, SOCS3, Ikbkb, Nfkbia, MAC1 and POMC were determined using inventoried primer and probe assays (Applied Biosystems, Foster City, CA) on an ABI 7500 Fast Real Time PCR System using Taqman ${ }^{\circ}$ Universal PCR Master Mix. The universal two-step RT-PCR cycling conditions used were: $50^{\circ} \mathrm{C}$ for $2 \mathrm{~min}, 95^{\circ} \mathrm{C}$ for $10 \mathrm{~min}$, followed by 40 cycles of $95^{\circ} \mathrm{C}$ for $15 \mathrm{~s}$ and $60^{\circ} \mathrm{C}$ for 1 min. Relative gene expression of individual samples run in duplicate was calculated by comparison to a relative standard curve and standardized by comparison to $18 \mathrm{~S}$ rRNA signal.

\section{Liquid chromatography mass spectrometry of oxidized phospholipids}

Lipids from brain of mice exposed to $\mathrm{FA}$ or $\mathrm{PM}_{2.5}$ were extracted three times with chloroform/methanol mixture (1:1) and combined extracts were evaporated to dryness under stream of nitrogen. Samples were stored under nitrogen atmosphere at $-80^{\circ} \mathrm{C}$ until analysis. Mass spectra were acquired in positive ion mode using Applied Biosystems 3200 QTRAP system coupled with electrospray ionization (TurbolonSpray) source. The spectrometer was optimized by infusion of PAPC $(25 \mathrm{nmol} / \mathrm{ml})$ and POVPC $(5 \mathrm{nmol} /$ $\mathrm{ml})$. All phospholipids were purchased from Avanti Polar Lipids Inc, (Alabaster, AL). The source parameters were set as follows: curtain gas (nitrogen), 10 psi; collision gas (nitrogen), medium; ion spray voltage $5000 \mathrm{~V}$; temperature $550^{\circ} \mathrm{C}$, ion spray voltage, $5000 \mathrm{~V}$; ion source gas 1 and 2, 30 and $50 \mathrm{psi}$, respectively. Optimized parameters for all phospholipids were: declustering potential, $50 \mathrm{~V}$; entrance 
potential, $10 \mathrm{~V}$ and collision energy, $50 \mathrm{eV}$. For analysis of brain extracts, samples were dissolved in mobile phase consisting of chloroform, methanol, water and trifluoroacetic acid (65:25:4:0.1, by vol). Lipids were characterized after isocratic separation on $5 \mathrm{~m}$ Zorbax RX-SIL $4.6 \mathrm{~mm} \times$ $250 \mathrm{~mm}$ HPLC column (Agilent Technologies, Santa Clara, CA) at $0.4 \mathrm{ml} / \mathrm{min}$ flow rate using Shimadzu LC-20 AD pump interfaced to a Shimadzu CBM-20A system controller. Mass spectrometer was operated in multiple reactions monitoring (MRM) positive ionization mode. Specific monitor Q1/Q3 ion pairs were $\mathrm{m} / \mathrm{z} 782184$ for PAPC and $\mathrm{m} / \mathrm{z} 594184$ for POVPC. Standard curves for all phospholipids were obtained in the same set of experiments by infusion of serially diluted PAPC and POVPC. All data were acquired and processed by Analyst software (version 1.4.2, Applied Biosystems, Foster City, CA).

\section{Data analysis}

Data are expressed as means \pm standard error of the mean unless otherwise indicated. For the analysis of hypothalamic inflammation biomarkers, linear regression was used with PM exposure, treatment group, and PM $\mathrm{x}$ treatment interaction as the independent variables. Based on our previous studies, we had an a priori hypothesis regarding the direction of the outcome. A one-tailed t-test was used to analyze the effect of 5-week or 8-week PM exposure on mRNA expression in hypothalamus. To examine the effect of PM exposure on glucose homeostasis, body weight, and food intake in each treatment group (PM and FA), a stratified analysis using linear regression (with PM exposure, treatment group, and their interaction) was initially performed at each time point of measurement. In addition, an overall repeated measures analysis was performed using all observations with covariates in the linear model: PM, treatment group, PM x treatment interaction, and time. For body weight and food intake, the analysis further adjusted for baseline measures $(0$ week) when available. For the measurements on energy metabolism/expenditure response, two analysis strategies were used - (1) taking the average over time (cycles) for each mouse and then using linear regression and (2) using repeated measures analysis, adjusting for time. For all repeated measures analyses, in each model a correlation structure was chosen based on the Akaike Information Criterion (AIC) value to account for the correlation between repeated measurements on the same mouse or mice staying in the same cage. A p-value of less than 0.05 was deemed statistically significant. All analyses were performed using R2.15.0.

\footnotetext{
Abbreviations

aCSF: artificial cerebrospinal fluid; CNS: Central nervous system; FA: Filtered air; IR: Insulin resistance; ITT: Insulin tolerance test; ICV: Intracerebroventricular; IPGTT: Intra-peritoneal glucose tolerance testing; OxPAPC: Oxidized 1-palmitoyl2-arachidonoyl-sn-glycero-3-phosphocholine; PM: Particulate matter; $\mathrm{PM}_{2.5}$ : Particulate matter $<2.5 \mu \mathrm{m}$ in aerodynamic diameter;
}

POMC: Proopiomelanocortin; RER: Respiratory exchanging ratio; SOCS: Suppressorof-cytokine signaling; HOMA-IR: Homeostasis model assessment of the IR index; Type II DM: Type II diabetes; VAT: Visceral adipose tissue.

\section{Competing interests}

The authors declare that they have no competing interests.

\section{Authors' contributions}

$C L, F L, Y B, A M, A W, T W, Z Y, S M$ and MM performed the experiments and contributed to acquisition of data. CL, ZY, YK, BM, and SM analyzed the data and interpreted the results. AW contributed to $\mathrm{PM}_{2.5}$ exposure of the animals. The manuscript was written by $C L$ and revised critically by $S R, Q S$, LS, MP and JTD. All authors read, corrected and approved the manuscript.

\section{Acknowledgements}

This work was supported by National Institute of Environmental Health Sciences (NIEHS) grants R01-ES-017290, R01-ES-015146, R01-ES-019616 (to Dr. Rajagopalan) and R01-ES-018900 (to Dr. Sun). It was also made possible by National Natural Science Foundation of China 81402646 , Zhejiang Provincial Natural Science Foundation of China LQ13H070002 (to Dr. Liu) and USEPA grant (to Dr. Rajagopalan and Dr. Harkema). Its contents are solely the responsibility of the grantee and do not necessarily represent the official views of the USEPA. Further, USEPA does not endorse the purchase of any commercial products or services mentioned in the publication.

\section{Author details}

${ }^{1}$ Department of Physiology, Hangzhou Normal University, Hangzhou, China. ${ }^{2}$ Wexner Medical Center, The Ohio State University, Columbus, OH, USA. ${ }^{3}$ Division of Cardiovascular Medicine, University of Maryland, Baltimore, MD, USA. ${ }^{4}$ Department of Biostatistics, University of Michigan, Ann Arbor, MI, USA. ${ }^{5}$ Department of Environmental Health Sciences, University of Michigan, Ann Arbor, MI, USA. ${ }^{6}$ Center for Integrative Toxicology, Michigan State University, Lansing, MI, USA.

Received: 16 April 2014 Accepted: 29 September 2014

Published online: 30 October 2014

\section{References}

1. Lim SS, Vos T, Flaxman AD, Danaei G, Shibuya K, Adair-Rohani H, Amann M, Anderson HR, Andrews KG, Aryee M, Atkinson C, Bacchus LJ, Bahalim AN, Balakrishnan K, Balmes J, Barker-Collo S, Baxter A, Bell ML, Blore JD, Blyth F, Bonner C, Borges G, Bourne R, Boussinesq M, Brauer M, Brooks P, Bruce NG, Brunekreef B, Bryan-Hancock C, Bucello C, et al: A comparative risk assessment of burden of disease and injury attributable to 67 risk factors and risk factor clusters in 21 regions, 1990-2010: a systematic analysis for the Global Burden of Disease Study 2010. Lancet 2012, 380:2224-2260.

2. Brook RD, Rajagopalan S, Pope CA 3rd, Brook JR, Bhatnagar A, Diez-Roux AV, Holguin F, Hong Y, Luepker RV, Mittleman MA, Peters A, Siscovick D, Smith SC Jr, Whitsel L, Kaufman JD, American Heart Association Council on Epidemiology and Prevention, Council on the Kidney in Cardiovascular Disease, and Council on Nutrition, Physical Activity and Metabolism: Particulate matter air pollution and cardiovascular disease: An update to the scientific statement from the American Heart Association. Circulation 2010, 121:2331-2378.

3. Brook RD, Xu X, Bard RL, Dvonch JT, Morishita M, Kaciroti N, Sun Q, Harkema J, Rajagopalan S: Reduced metabolic insulin sensitivity following sub-acute exposures to low levels of ambient fine particulate matter air pollution. Sci Total Environ 2013, 448:66-71.

4. Rajagopalan S, Brook RD: Air pollution and type 2 diabetes: mechanistic insights. Diabetes 2012, 61:3037-3045.

5. Sun $Q$, Yue P, Deiuliis JA, Lumeng CN, Kampfrath T, Mikolaj MB, Cai Y, Ostrowski MC, Lu B, Parthasarathy S, Brook RD, Moffatt-Bruce SD, Chen LC, Rajagopalan S: Ambient air pollution exaggerates adipose inflammation and insulin resistance in a mouse model of diet-induced obesity. Circulation 2009, 119:538-546.

6. Zheng Z, Xu X, Zhang X, Wang A, Zhang C, Huttemann M, Grossman LI, Chen LC, Rajagopalan S, Sun Q, Zhang K: Exposure to ambient particulate matter induces a NASH-like phenotype and impairs hepatic glucose metabolism in an animal model. J Hepatol 2013, 58:148-154.

7. Hotamisligil GS: Endoplasmic reticulum stress and the inflammatory basis of metabolic disease. Cell 2010, 140:900-917. 
8. Hotamisligil GS: Inflammation and metabolic disorders. Nature 2006, 860:867

9. Gregor MF, Hotamisligil GS: Inflammatory mechanisms in obesity. Annu Rev Immunol 2011, 29:415-445.

10. De Souza CT, Araujo EP, Bordin S, Ashimine R, Zollner RL, Boschero AC, Saad $M J$, Velloso LA: Consumption of a fat-rich diet activates a proinflammatory response and induces insulin resistance in the hypothalamus. Endocrinology 2005, 146:4192-4199.

11. Thaler JP, Choi SJ, Schwartz MW, Wisse BE: Hypothalamic inflammation and energy homeostasis: resolving the paradox. Front Neuroendocrinol 2010, 31:79-84.

12. Posey KA, Clegg DJ, Printz RL, Byun J, Morton GJ, Vivekanandan-Giri A, Pennathur S, Baskin DG, Heinecke JW, Woods SC, Schwartz MW, Niswender KD: Hypothalamic proinflammatory lipid accumulation, inflammation, and insulin resistance in rats fed a high-fat diet. Am J Physiol Endocrinol Metab 2009, 296:E1003-E1012.

13. Thaler JP, Yi CX, Schur EA, Guyenet SJ, Hwang BH, Dietrich MO, Zhao X, Sarruf DA, Izgur V, Maravilla KR, Nguyen HT, Fischer JD, Matsen ME, Wisse BE, Morton GJ, Horvath TL, Baskin DG, Tschöp MH, Schwartz MW: Obesity is associated with hypothalamic injury in rodents and humans. J Clin Invest 2012, 122:153-162

14. Julio-Pieper M, O'Mahony CM, Clarke G, Bravo JA, Dinan TG, Cryan JF: Chronic stress-induced alterations in mouse colonic 5-HT and defecation responses are strain dependent. Stress 2012, 15:218-226.

15. Zhang X, Zhang G, Zhang H, Karin M, Bai H, Cai D: Hypothalamic IKKbeta/ NF-kappaB and ER stress link overnutrition to energy imbalance and obesity. Cell 2008, 135:61-73.

16. Arruda AP, Milanski M, Coope A, Torsoni AS, Ropelle E, Carvalho DP, Carvalheira JB, Velloso LA: Low-grade hypothalamic inflammation leads to defective thermogenesis, insulin resistance, and impaired insulin secretion. Endocrinology 2011, 152:1314-1326.

17. Furukawa S, Fujita T, Shimabukuro M, Iwaki M, Yamada Y, Nakajima Y, Nakayama O, Makishima M, Matsuda M, Shimomura I: Increased oxidative stress in obesity and its impact on metabolic syndrome. J Clin Invest 2004, 114:1752-1761.

18. Block ML, Calderon-Garciduenas L: Air pollution: mechanisms of neuroinflammation and CNS disease. Trends Neurosci 2009, 32:506-516.

19. Block ML, Elder A, Auten RL, Bilbo SD, Chen H, Chen JC, Cory-Slechta DA, Costa D, Diaz-Sanchez D, Dorman DC, Gold DR, Gray K, Jeng HA, Kaufman JD, Kleinman MT, Kirshner A, Lawler C, Miller DS, Nadadur SS, Ritz B, Semmens EO, Tonelli LH, Veronesi B, Wright RO, Wright RJ: The outdoor air pollution and brain health workshop. Neurotoxicology 2012, 33:972-984.

20. Fonken LK, Xu X, Weil ZM, Chen G, Sun Q, Rajagopalan S, Nelson RJ: Air pollution impairs cognition, provokes depressive-like behaviors and alters hippocampal cytokine expression and morphology. Mol Psychiatry 2011, 16:987-995. 973.

21. Thaler JP, Schwartz MW: Minireview: Inflammation and obesity pathogenesis: the hypothalamus heats up. Endocrinology 2010, 151:4109-4115.

22. Dostert C, Petrilli V, Van Bruggen R, Steele C, Mossman BT, Tschopp J: Innate immune activation through Nalp3 inflammasome sensing of asbestos and silica. Science 2008, 320:674-677.

23. Kampfrath T, Maiseyeu A, Ying Z, Shah Z, Deiuliis JA, Xu X, Kherada N, Brook RD, Reddy KM, Padture NP, Parthasarathy S, Chen LC, Moffatt-Bruce S, Sun Q, Morawietz H, Rajagopalan S: Chronic fine particulate matter exposure induces systemic vascular dysfunction via NADPH oxidase and TLR4 pathways. Circ Res 2011, 108:716-726.

24. Denis RG, Arruda AP, Romanatto T, Milanski M, Coope A, Solon C, Razolli DS, Velloso LA: TNF-alpha transiently induces endoplasmic reticulum stress and an incomplete unfolded protein response in the hypothalamus. Neuroscience 2010, 170:1035-1044.

25. Combadiere C, Potteaux S, Rodero M, Simon T, Pezard A, Esposito B, Merval R, Proudfoot A, Tedgui A, Mallat Z: Combined inhibition of CCL2, CX3CR1, and CCR5 abrogates Ly6C(hi) and Ly6C(lo) monocytosis and almost abolishes atherosclerosis in hypercholesterolemic mice. Circulation 2008 117:1649-1657.

26. Henderson RB, Hobbs JA, Mathies M, Hogg N: Rapid recruitment of inflammatory monocytes is independent of neutrophil migration. Blood 2003, 102:328-335.

27. Lumeng CN, Deyoung SM, Bodzin JL, Saltiel AR: Increased inflammatory properties of adipose tissue macrophages recruited during diet-induced obesity. Diabetes 2007, 56:16-23.
28. Lumeng CN, Bodzin JL, Saltiel AR: Obesity induces a phenotypic switch in adipose tissue macrophage polarization. J Clin Invest 2007, 117:175-184.

29. Tsou CL, Peters W, Si Y, Slaymaker S, Aslanian AM, Weisberg SP, Mack M, Charo IF: Critical roles for CCR2 and MCP-3 in monocyte mobilization from bone marrow and recruitment to inflammatory sites. J Clin Invest 2007, 117:902-909

30. Weisberg SP, Hunter D, Huber R, Lemieux J, Slaymaker S, Vaddi K, Charo I, Leibel RL, Ferrante AW Jr: CCR2 modulates inflammatory and metabolic effects of high-fat feeding. J Clin Invest 2006, 116:115-124.

31. Weisberg SP, McCann D, Desai M, Rosenbaum M, Leibel RL, Ferrante AW Jr: Obesity is associated with macrophage accumulation in adipose tissue. J Clin Invest 2003, 112:1796-1808.

32. Liu C, Xu X, Bai Y, Wang TY, Rao X, Wang A, Sun L, Ying Z, Gushchina L, Maiseyeu A, Morishita M, Sun Q, Harkema JR, Rajagopalan S: Air pollution-mediated susceptibility to inflammation and insulin resistance: influence of CCR2 pathways in mice. Environ Health Perspect 2014, 122:17-26.

33. Ito D, Imai Y, Ohsawa K, Nakajima K, Fukuuchi Y, Kohsaka S: Microgliaspecific localisation of a novel calcium binding protein, Iba1. Brain Res Mol Brain Res 1998, 57:1-9.

34. Parton LE, Ye CP, Coppari R, Enriori PJ, Choi B, Zhang CY, Xu C, Vianna CR, Balthasar N, Lee CE, Elmquist JK, Cowley MA, Lowell BB: Glucose sensing by POMC neurons regulates glucose homeostasis and is impaired in obesity. Nature 2007, 449:228-232.

35. Smart JL, Tolle V, Low MJ: Glucocorticoids exacerbate obesity and insulin resistance in neuron-specific proopiomelanocortin-deficient mice. J Clin Invest 2006, 116:495-505.

36. Xu X, Yavar Z, Verdin M, Ying Z, Mihai G, Kampfrath T, Wang A, Zhong M, Lippmann M, Chen LC, Rajagopalan S, Sun Q: Effect of early particulate air pollution exposure on obesity in mice: role of p47phox. Arterioscler Thromb Vasc Biol 2010, 30:2518-2527.

37. Thompson AM, Zanobetti A, Silverman F, Schwartz J, Coull B, Urch B, Speck M, Brook JR, Manno M, Gold DR: Baseline repeated measures from controlled human exposure studies: associations between ambient air pollution exposure and the systemic inflammatory biomarkers IL-6 and fibrinogen. Environ Health Perspect 2010, 118:120-124.

38. Mutlu GM, Green D, Bellmeyer A, Baker CM, Burgess Z, Rajamannan N, Christman JW, Foiles N, Kamp DW, Ghio AJ, Chandel NS, Dean DA, Sznajder $J \mathrm{Jl}$, Budinger GR: Ambient particulate matter accelerates coagulation via an IL-6-dependent pathway. J Clin Invest 2007, 117:2952-2961.

39. Painschab MS, Davila-Roman VG, Gilman RH, Vasquez-Villar AD, Pollard SL, Wise RA, Miranda JJ, Checkley W: Chronic exposure to biomass fuel is associated with increased carotid artery intima-media thickness and a higher prevalence of atherosclerotic plaque. Heart 2013, 99:984-991.

40. Sun Q, Wang A, Jin X, Natanzon A, Duquaine D, Brook RD, Aguinaldo JG Fayad ZA, Fuster V, Lippmann M, Chen LC, Rajagopalan S: Long-term air pollution exposure and acceleration of atherosclerosis and vascular inflammation in an animal model. JAMA 2005, 294:3003-3010.

41. Ryan KK, Woods SC, Seeley RJ: Central nervous system mechanism linking the consumption of palatable high-fat diets to the defense of greater adiposity. Cell Metab 2012, 15:137-149.

42. Nakane H: Translocation of particles deposited in the respiratory system: a systematic review and statistical analysis. Environ Health Prev Med 2012, 17:263-274.

43. Olofsson PS, Rosas-Ballina M, Levine YA, Tracey KJ: Rethinking inflammation: neural circuits in the regulation of immunity. Immunol Rev 2012, 248:188-204.

44. Cai D: NFkappaB-mediated metabolic inflammation in peripheral tissues versus central nervous system. Cell Cycle 2009, 8:2542-2548.

45. Obici S, Zhang BB, Karkanias G, Rossetti L: Hypothalamic insulin signaling is required for inhibition of glucose production. Nat Med 2002, 8:1376-1382.

46. Vanpatten S, Karkanias GB, Rossetti L, Cohen DE: Intracerebroventricular leptin regulates hepatic cholesterol metabolism. Biochem J 2004, 379:229-233.

47. Reyes-Garcia MG, Garcia-Tamayo F: A neurotransmitter system that regulates macrophage pro-inflammatory functions. J Neuroimmunol 2009, 216:20-31.

48. Romanatto T, Roman EA, Arruda AP, Denis RG, Solon C, Milanski M, Moraes JC, Bonfleur ML, Degasperi GR, Picardi PK, Hirabara S, Boschero AC, Curi R, Velloso LA: Deletion of tumor necrosis factor-alpha receptor 1 (TNFR1) 
protects against diet-induced obesity by means of increased thermogenesis. J Biol Chem 2009, 284:36213-36222.

49. Purkayastha S, Zhang G, Cai D: Uncoupling the mechanisms of obesity and hypertension by targeting hypothalamic IKK-beta and NF-kappaB. Nat Med 2011, 17:883-887.

50. Liu C, Bai Y, Xu X, Sun L, Wang A, Wang TY, Maurya SK, Periasamy M, Morishita M, Harkema J, Ying Z, Sun Q, Rajagopalan S: Exaggerated effects of particulate matter air pollution in genetic type II diabetes mellitus. Part Fibre Toxicol 2014, 11:27.

51. Onai Y, Suzuki J, Kakuta T, Maejima Y, Haraguchi G, Fukasawa H, Muto S, Itai A, Isobe M: Inhibition of IkappaB phosphorylation in cardiomyocytes attenuates myocardial ischemia/reperfusion injury. Cardiovasc Res 2004, 63:51-59.

52. Huang W, Bansode RR, Bal NC, Mehta M, Mehta KD: Protein kinase Cbeta deficiency attenuates obesity syndrome of ob/ob mice by promoting white adipose tissue remodeling. J Lipid Res 2012, 53:368-378.

53. Zhong J, Rao X, Deiuliis J, Braunstein Z, Narula V, Hazey J, Mikami D, Needleman B, Satoskar AR, Rajagopalan S: A potential role for dendritic cell/ macrophage-expressing DPP4 in obesity-induced visceral inflammation. Diabetes 2013, 62:149-157.

doi:10.1186/s12989-014-0053-5

Cite this article as: Liu et al:: Central IKK $\beta$ inhibition prevents air pollution mediated peripheral inflammation and exaggeration of type II diabetes. Particle and Fibre Toxicology 2014 11:53.

\section{Submit your next manuscript to BioMed Central and take full advantage of:}

- Convenient online submission

- Thorough peer review

- No space constraints or color figure charges

- Immediate publication on acceptance

- Inclusion in PubMed, CAS, Scopus and Google Scholar

- Research which is freely available for redistribution 